\title{
Paraneoplastic Neurological Syndrome in Fallopian Tube Cancer
}

\section{Paraneoplastisches neurologisches Syndrom beim Tubenkarzinom}

Authors

Affiliations
E. Maas ${ }^{1}$, T. Skoberne ${ }^{2}$, A. Werner ${ }^{1}$, S. Braun ${ }^{3}$, C. Jackisch ${ }^{1}$

1 Gynäkologie und Geburtshilfe, SanaKlinikum Offenbach, Offenbach

${ }^{2}$ Neurologie, SanaKlinikum Offenbach, Offenbach

${ }^{3}$ Pathologie, SanaKlinikum Offenbach, Offenbach

\begin{abstract}
Key words
- paraneoplastic syndrome

- tubal carcinoma

onconeuronal antibodies

Schlüsselwörter

- paraneoplastisches Syndrom

- Tubenkarzinom

- onkoneuronaler Antikörper
\end{abstract}

Deutschsprachige Zusatzinformationen online abrufbar unter: www.thieme-connect.de/ ejournals/toc/gebfra

received 28.4.2014

revised $\quad 7.7 .2014$

accepted 28.7.2014

\section{Bibliography}

DOI http://dx.doi.org/ 10.1055/s-0034-1383041

Geburtsh Frauenheilk 2014; 74: 950-953 @ Georg Thieme

Verlag KG Stuttgart · New York . ISSN 0016-5751

\section{Correspondence}

Dr. Ellen Maas

SanaKlinikum Offenbach

Gynäkologie und Geburtshilfe

Starkenburgring 66

63069 Offenbach

ellen-maas@gmx.de

\section{Abstract \\ $\nabla$}

We report on a rare case of paraneoplastic syndrome (PS) that was discovered on completion of diagnostic work-up to be an undifferentiated fallopian tube carcinoma. A 49-year-old Caucasian woman was admitted to neurology with vertigo, gait ataxia and dysarthria, transient ischaemic attack (TIA) and stroke were quickly excluded. Indicative for the further diagnosis of a paraneoplastic syndrome was the identification of onconeuronal antibodies the detection of which can be associated with certain tumour entities. The strongly positive anti-Yo antibody that is formed above all by breast and lung cancers as well as ovarian cancer led to a corresponding staging. The tumour markers CEA, CA 125 and CA 15-3 were in the normal ranges. Mammography and thorax CT were also unremarkable; on transvaginal sonography the internal genitals were inconspicuous except for a follicular cyst on the left. On abdominal CT the only conspicuous finding was a $1.5 \mathrm{~cm}$ ovarian cyst. After consensual agreement a bilateral laparoscopic adenexectomy was performed but with unremarkable abdominal findings. The histological examination confirmed a right-sided undifferentiated tubal carcinoma with the provisional classification FIGO IIA. After a stage-related staging operation, the final classification was found to be the FIGO-IIIC stage on account of positive retroperitoneal lymph nodes. Thus adjuvant chemotherapy with 6 cycles of carboplatin and paclitaxel was performed. By means of a timely, guideline-conform therapy for tubal carcinoma, the neurological symptoms and, above all, the dysarthria could be improved after 10 months.

\section{Zusammenfassung \\ $\nabla$}

Wir berichten über den seltenen Fall eines paraneoplastischen Syndroms (PS), das sich nach Abschluss der Diagnostik als undifferenziertes Tubenkarzinom herausstellte. Eine 49-jährige kaukasische Patientin wird mit Drehschwindel, Gangataxie und Dysarthrie neurologisch aufgenommen, eine transitorisch ischämische Attacke (TIA) und ein Apoplex können schnell ausgeschlossen werden. Wegweisend in der weiteren Diagnostik des paraneoplastischen Syndroms war die Bestimmung onkoneuronaler Antikörper, deren Nachweis mit bestimmten Tumorentitäten assoziiert sein kann. Der stark positive Anti-Yo-Antikörper, der v.a. von Mammaund Lungenkarzinomen sowie Ovarialkarzinomen gebildet wird, veranlasste ein entsprechendes Staging. Die Tumormarker CEA, CA 125 und CA 15-3 waren normwertig. Ebenso die Mammografie und das Thorax-CT, in der Transvaginalsonografie stellte sich das innere Genitale bis auf eine Follikelzyste links unauffällig dar. In der Abdomen-CT verblieb eine ca. 1,5 cm große Ovarialzyste links als einziger auffälliger Befund. Nach konsensualer Einwilligung erfolgte die laparoskopische Adnexektomie beidseits bei makroskopisch unauffälligem intraabdominalem Situs. Die histologische Untersuchung bestätigte ein undifferenziertes Tubenkarzinom rechts mit der vorläufigen Klassifikation FIGO IIA. Nach stadiengerechter Staging-Operation ergab die endgültige Klassifikation aufgrund positiver retroperitonealer Lymphknoten ein FIGO-IIIC-Stadium. Somit wurde die adjuvante Chemotherapie mit 6 Zyklen Carboplatin und Paclitaxel durchgeführt. Mittels frühzeitiger leitliniengerechter Therapie des Tubenkarzinoms konnten die neurologischen Symptome, v.a. die Dysarthrie, nach 10 Monaten gebessert werden. 


\section{Introduction}

\section{$\nabla$}

Paraneoplastic neurological syndromes encompass numerous neurological symptoms that mostly manifest prior to the diagnosis of a tumour. In the past decades the number of and knowledge about antineuronal or, respectively, onconeuronal antibodies that are expressed by malignant tumours have increased markedly. These antibodies are directed against neural antigens and thus lead to neurological symptoms. The most common designation is derived from the abbreviated name of the index patient. The anti-Yo antibodies are otherwise known as anti-Purkinje-cell antibodies (APCA) because they react with components of Purkinje cells in the cerebellum. They comprise an IgG antibody with a molecular weight of ca. 150 kDalton.

Paraneoplastic neurological syndromes are rare and occur in less than $1 \%$ of all malignant tumour patients. However, diagnosis and treatment are important since the clinical symptoms that are caused by paraneoplastic neurological syndromes are often particularly severe while also leading to the correct diagnosis of a tumour disease that often responds well to treatment or is even curable.

On suspicion of a paraneoplastic syndrome with cerebral cerebellar participation, antibodies against intracellular antigens, socalled onconeuronal antibodies (Hu, Yo, Ri, CV2, amphiphysin) as well as antibodies against surface antigens (NMDA receptor, AMPA receptor, GABA receptor) should be determined.

Not only anti-HU but also anti-Ri antibodies are targeted at neuronal cell nuclei and are accordingly known as anti-neuronal nuclear antibodies (ANNA). The anti-HU antibodies (ANNA-1) have been reported in paraneoplastic neurological symptoms such as encephalomyelitis, limbic encephalitis and also in paraneoplastic cerebellar degeneration (PCD) and are triggered by small-cell lung cancer. Symptoms of brain stem encephalitis are also caused by anti-Ri-(ANNA-2) antibodies and have also been observed in breast cancer as well as small-cell lung cancer. The Ma2 antibody is also found in limbic encephalitis and brain stem encephalitis. Antibodies against surface antigens occur not only in autoimmune diseases but also within the framework of a paraneoplastic syndrome (e.g., limbic encephalitis).

The anti-Yo antibodies detected in this case report are almost exclusively associated with gynaecological tumours (breast cancer and ovarian cancer). In addition, these antibodies are sporadically described in women and men with adenocarcinomas, e.g., of the lungs or lymphomas [1].

The clinical syndrome that is triggered by anti-Yo antibodies is paraneoplastic cerebellar degeneration. With a prevalence of about $15 \%$, it is the second most frequent paraneoplastic antibody referred to all paraneoplastic syndromes in the European Register PNS Euronet [2].

Mostly in the framework of the anti-Yo syndrome, acute to subacute (a few days to 4 months) cerebellar symptoms with stance and gait ataxia, nystagmus and dysarthria occur. Sometimes sensitivity disorders in patients have been described, due to damage to white columns [3].

CSF diagnostics often lead to the detection of oligoclonal bands and thus to confirmation of an immune process. In cranial MRI, atrophy of the cerebellum is only seen in advanced stages. The Yo-1 antibody points in the right direction; it is triggered by antigens of the associated tumour and cross-reacts with components of Purkinje cells of the cerebellum [4]. In histological samples, degeneration and in many cases complete loss of Purkinje cells is seen together with atrophy of the molecular and stratum granulosum layers of the cerebellum together with a reactive proliferation of astrocytes. Occasionally an atrophy of the posterior white columns and the corticospinal tracts is also apparent.

When onconeuronal antibodies have been detected, an intensive search for a tumour is mandatory; a cure is only possible through removal of the malignant process. An immunosuppressive therapy with corticoids, chemotherapy or immunomodulation to influence the autoimmune processes (to slow down the progression of cerebellar degeneration) is only rarely useful in cases of antibodies directed against intracellular antigens. The disease course as a whole is determined more by the neurological impairments than by the triggering tumour. In our case report a tubal carcinoma triggered the neurological symptoms.

With an incidence of $0.5 \%$ the tubal carcinoma belongs rather to the rare genital cancers. Staging and therapy are similar to those for ovarian carcinomas. The majority of these carcinomas are diagnosed in an advanced stage. Both carcinomas have about the same age distribution, often occur in nulliparous women and frequently exhibit a serous-papillary histology [5].

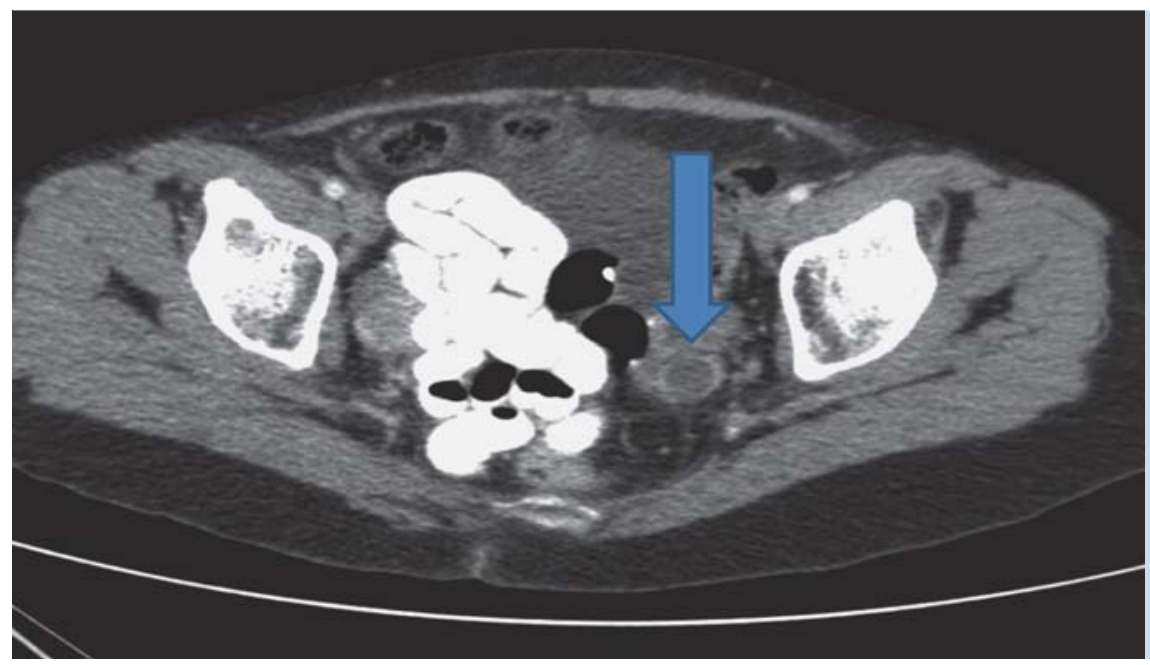

Fig. 1 Abdominal CT of the patient. Arrow: ovarian cyst on the left side. 


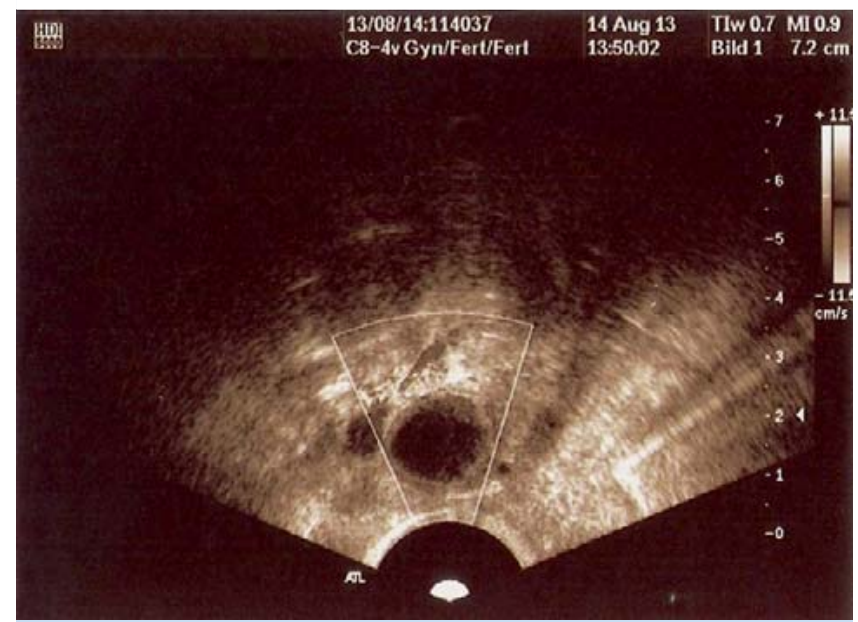

Fig. 2 Transvaginal sonography: harmless follicular cyst on the left side.

\section{Case Report \\ $\nabla$}

A 49-year-old female patient presented in the emergency unit with a 1-week history of progressive vertigo, dysarthria and coordination disorders in the form a gait ataxia. On account of these symptoms she was admitted to the neurology department and diagnostics to exclude brain infarct or multiple sclerosis by means of MRI were undertaken. However, no evidence of a fresh infarct demarcation, intracranial haemorrhage, cranial oedema, and disorder of CSF circulation or indications for an acute multiple sclerosis was found. An extended diagnostic work-up by means of cranial MRI gave age-appropriate findings. A spinal tap gave remarkable findings with 50 cells/ $\mu \mathrm{L}$ and elevated protein content with detection of oligoclonal bands and thus the first suggestion for an inflammatory process of the central nervous system. The determination of onconeuronal antibodies in the patient's blood was positive for anti-Yo antibodies and thus enabled the diagnosis of a paraneoplastic neurological syndrome. Since anti-Yo antibodies are associated above all with gynaecological tumours the clarification reported here was carried out. Senological investigations were unremarkable. Tumour markers, especially CA 125 with a value of $13.7 \mathrm{kU} / \mathrm{L}$ (normal range under $35 \mathrm{kU} / \mathrm{L}$ ), were not elevated. An abdominal CT scan revealed an $1.5 \mathrm{~cm}$ ovarian cyst on the left with thin walls that was considered to be conspicuous after hysterectomy ( Fig. 1). This had previously been assessed as a harmless follicular retention cyst on transvaginal sonography (๑ Fig. 2).

Since all further staging examinations did not provide any suspicious space-occupying lesions, a laparoscopic bilateral adnexectomy to exclude carcinoma of the fallopian tubes or, respectively, of the ovaries was discussed consensually. The abdominal situation on laparoscopy was described as follows: there were bilateral adhesions with the intestine and the adnexa. The ovaries were macroscopically unremarkable, on the right there was a small conglomerate tumour between the ovary and the fallopian tube. In the absence of free fluid in the Douglas space, a flush cytology sample was taken.

The histological examination revealed an undifferentiated carcinoma in the right fallopian tube with a diameter of $1.7 \mathrm{~cm}$ and subtotal obliteration of the extended lumen and infiltration to the tube wall in continuitatem into the mesosalpingeal soft tissue. There was also a tumour manifestation of ca. $0.5 \mathrm{~cm}$ in the right ovary ( $\bullet$ Figs. $3 \mathbf{a}$ and $\mathbf{b}$ ).

On the basis of this diagnosis a subsequent staging laparotomy with peritonectomy, omentectomy and both pelvic and paraaortic lymphadenectomy was performed. The final TNM classification (7th edition, 2010) was as follows: pT2a pN1 (1/37 LK) cM0, G3 L0 V0 R0, FIGO IIIC. An adjuvant chemotherapy with 6 cycles of carboplatin and paclitaxel was initiated after the unremarkable postoperative course. From the 2nd cycle onwards bevacizumab was added. After 3 cycles of chemotherapy the first improvements of the patient's neurological symptoms were observed. An additional neurological rehabilitation after the successful chemotherapy is important.

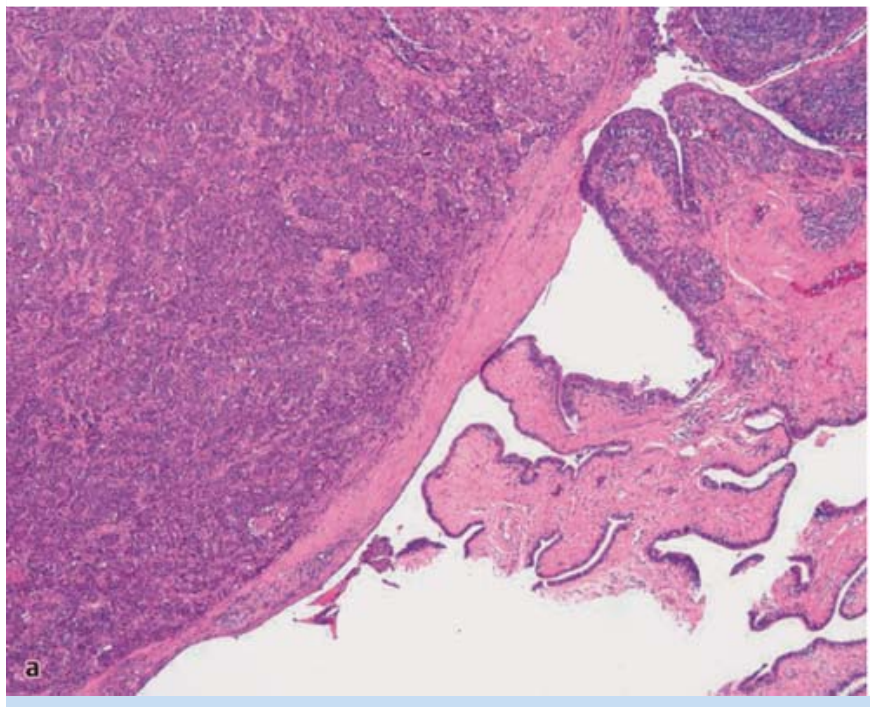

Fig. $\mathbf{3} \mathbf{a}$ and $\mathbf{b}$ a Section of the right uterine tube with fimbrian funnel (H\&E staining, 1:50). b Tumour cells with numerous mitoses as morpholog-

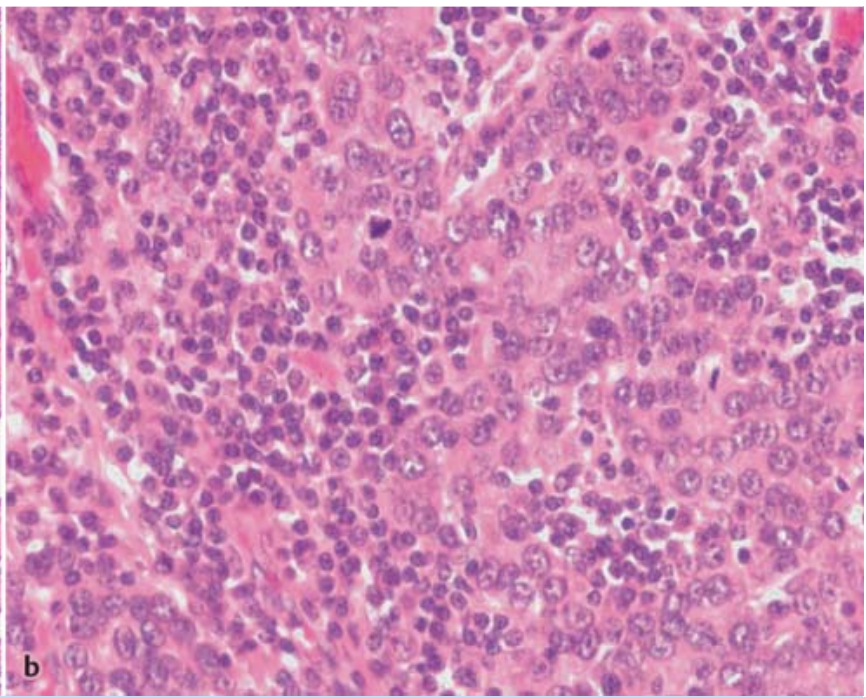

ical correlate of the poor differentiation of the tubal carcinoma ( $H$ \& E staining, $1: 100)$. 


\section{Discussion}

\section{$\nabla$}

Primary fallopian tube carcinomas amount to $0.14-1.8 \%$ of all genital carcinomas [6].

To date about 2000 cases of primary fallopian tube carcinoma have been described world-wide [7]. To what extent the term "primary fallopian tube carcinoma" will be valid in the future is, however, questionable. Thus, occult invasive and intraepithelial lesions of the fallopian tube have been found, so-called serous intraepithelial carcinomas (STICs) or serous intraepithelial lesions of the fallopian tube (STILs). These discoveries support the hypothesis that an origin of these (high grade) serous ovarian carcinomas are just these precursor lesions of the fallopian tubes [8]. These early carcinomas are above all localised in the fimbria so that the anatomic proximity as well as adhesions between tube and ovary favour the transmission of these invasive cells. A twopath model for the molecular pathogenesis of ovarian carcinomas is currently being discussed, namely on the one hand via borderline tumours of ovarian epithelium, which develop into serous, mucinous endometrial or clear cell carcinomas and on the other hand via STICs and STILs [8].

In the case of the remarkable adnexa findings on the left, the histological work-up furnished an unremarkable finding. The tube carcinoma is located on the contralateral adnexa that remained inconspicuous on imaging diagnostics and clinically. Lesions such as STIC or STIL were not found in our case. Finally, the tumour stage was assigned as IIIC with the consecutive indication for chemotherapy.

After final diagnosis of the tubal carcinoma, the further therapy was in accord with the S3 guidelines for ovarian carcinoma. Accordingly a staging laparotomy was performed as the next step [9].

Our patient was able to complete the chemotherapy according to protocol. Whereas the neurological symptoms improved only very slowly in the inpatient postoperative course, better progress, especially with regard to the dysarthria. could be seen after successful completion of the chemotherapy. The gait ataxia and problems above all with fine motor skills still impact on the patient's daily activities. Complete rehabilitation is unlikely because this is a case of cerebellar degeneration triggered by the tumourassociated antibodies.

There are 4 further cases in which a PCD has ultimately led to the diagnosis of a fallopian tube carcinoma. In all patients double vision was reported as the first symptom and hints of gynaecological tumour could not be obtained either by imaging methods or by elevated tumour markers [10]. 13 case reports have been published in connection with an ovarian carcinoma and interestingly in 5 of these case reports a PCD occurred one year after the first diagnosis and therapy for the ovarian carcinoma [11-15]. Even after stage-appropriate therapy for the malignant tumour and even with administration of immunoglobulins or immunosuppressive agents, most of these patients could only be partly relieved of their neurological symptoms. In some cases progress of the cerebellar degeneration was stopped while in other cases the symptoms deteriorated; cerebral metastases occurred additionally which led to an early mortality [16].
In summary, in this case report the neurological (cerebellar) symptoms were assessed as paraneoplastic syndrome and the cause diagnosed by determination of the correct onconeuronal antibody panel. Imaging diagnostics merely revealed one lesion on the left adnexa in this premenopausal 49-year-old patient. Thus the decision for laparoscopy with lavage (negative) and bilateral adnexectomy was made.

\section{Conflict of Interest}

$\nabla$

None.

\section{References}

1 Darnell JC, Albert ML, Darnell RB. Cdr2, a target antigen of naturally occurring human tumor immunity, is widely expressed in gynecological tumors. Cancer Res 2000; 60: 2136-2139

2 Giometto B, Grisold W, Vitaliani R et al. Paraneoplastic neurologic syndrome in the PNS Euronetwork database: a European study from 20 centers. Arch Neurol 2010; 67: 330-335

3 Graus F, Delattre JY, Antoine JC et al. Recommended diagnostic criteria for paraneoplastic neurological syndromes. J Neurol Neurosurg Psychiatry 2004; 75: 1135-1140

4 Shams'ili S, Grefkens J, de Leeuw B et al. Paraneoplastic cerebellar degeneration associated with antineuronal antibodies: analysis of $50 \mathrm{pa}-$ tients. Brain 2003; 126: 1409-1418

5 Schneider C, Weight E, Perucchini D et al. Primary carcinoma of the fallopian tube. A report of 19 cases with literature review. Eur J Gynaecol Oncol 2000; 21: 578-582

6 Riska A, Leminen A, Pukkala E et al. Sociodemographic determinants of incidence of primary fallopian tube carcinoma, Finland 1953-97. Int J Cancer 2003; 104: 643-645

7 Oliveira C, Duarte H, Bartosch C et al. Small fallopian tube carcinoma with extensive upper abdominal dissemination: a case report. J Med Case Rep 2013; 7: 252

8 Gross AI, Kurman RJ, Vang R et al. Precursor lesions of high-grade serous ovarian carcinoma: morphological and molecular characteristics. J Oncol 2010; 2010: 126295

9 Vergote I, Tropé CG, Amant F et al. Neoadjuvant chemotherapy or primary surgery in stage IIIC or IV ovarian cancer. N Engl J Med 2010; 363: 943-953

10 Tanaka Y, Suzuki N, Takao M et al. Paraneoplastic cerebellar degeneration with fallopian tube adenocarcinoma. Gynecol Oncol 2005; 99: 500-503

11 David YB, Warner E, Levitan $M$ et al. Autoimmune paraneoplastic cerebellar degeneration in ovarian carcinoma patients treated with plasmapheresis and immunoglobulin. A case report. Cancer 1996; 78: 2153-2156

12 Holzmann P, Holy D, Stillhard G et al. Paraneoplastic cerebellar degeneration (PCD) with anti-Yo antibodies in ovarian carcinoma. Schweiz Med Wochenschr 1998; 128: 906-908

13 Goldstein BH, Birk CL, Van Houten M et al. Ovarian cancer and late onset paraneoplastic cerebellar degeneration. Arch Gynecol Obstet 2009; 280: 99-101

14 Caliandro P, Luigetti M, Ricci E et al. Cerebellar degeneration and ocular myasthenia gravis in a patient with recurring ovarian carcinoma. Neurol Sci 2010; 31: 71-81

15 Bradley WH, Dottino PR, Rahaman J. Paraneoplastic cerebellar degeneration in ovarian carcinoma: case report with review of immune modulation. Int J Gynecol Cancer 2008; 18: 1364-1367

16 Stepanic V, Matkovic V, Corusic A et al. Ovarian cancer: PCD and brain metastases. Coll Antropoll 2007; 31: 633-636 